\title{
ARISTOPHANES EN DIE TWEEDE BEDRYF VAN BREYTEN BREYTENBACH SE BOKLIED: 'N VERKENNING
}

\author{
P J Conradie (Universiteit van Stellenbosch)
}

Breyten Breytenbach se drama Boklied het in die jongste tyd groot opspraak verwek, nie alleen vanweë die tonele van naaktheid en seks nie, maar óók vanweë daarvan. Die verwysingsveld is so breed dat die deursnee-toeskouer nie altyd die kloutjie by die oor kan bring nie. Om hierdie rede het Hermien Dommisse (1998:13) op ietwat melodramatiese wyse verklaar: "Boklied kan die dood van die Afrikaanse toneel inlui." Sy motiveer dit so: "Boklied faal as aanvaarbare toneel uit die staanspoor omdat Breytenbach as draers van sy woord toneelspelerverteenwoordigers uit die Griekse en Egiptiese mitologie kies wat vir die gehoor totale vreemdelinge is en met wie hulle hul nie kan identifiseer nie." Daarteenoor beweer Helize van Vuuren (Norval 1998:5) in haar professorale intreerede dat hierdie drama "'n intellektuele en kreatiewe inspuiting vir die nogal dormante Afrikaanse drama is". Sy wys ook op die Dionisiese gees van die drama.

Die invloed van die oud-Griekse letterkunde en kultuur is inderdaad merkbaar

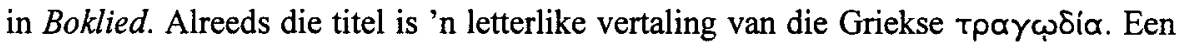
van die moontlike verklarings is dat ' $n$ bok by die opvoerings geoffer is. ' $n$ Tragedie sou dan "die lied van die sterwende bok wees", soos Jan Rabie dit op 'n keer gestel het. Die vertoning van die fallus is ook ' $n$ tipiese kenmerk van die Ou Komedie. Maar dit is veral in die tweede bedryf dat die Griekse invloed na vore kom, want dit is 'n verwerking van 'n gedeelte van Aristaphanes se komedie Die voëls. Dit is hierdie bedryf wat in hierdie artikel ondersoek sal word om te sien wat die dramaturg van die oorspronklike werk gemaak het. Daar moet beklemtoon word dat dit 'n voorlopige ondersoek is, want oor hierdie duistere drama sal daar nog baie geskryf word.

Die voëls is een van die sprankelendste komedies van Aristophanes waar hy sy fantasie in 'n groter mate as gewoonlik vrye teuels gegee het. Die verloop van die handeling is kortliks soos volg: Twee Atheners, Peisetairos ${ }^{1}$ en Euelpides, is moeg van die voortdurende hofsake waarop die Atheners so versot is, en verlaat die stad op soek na 'n plek waar hulle rustig kan woon. Hulle gaan na die woonplek van die voëls, veral van die hoep-hoep wat oorspronklik die mens Tereus was. ${ }^{2}$ As sy kneg, ook 'n voël, te voorskyn kom, laat hulle die hoep-hoep roep. Dan vertel hulle aan hom na watter soort land hulle soek, en ná verskeie voorstelle vra hulle hoedanig sy lewe onder die voëls is. Dan kom Peisetairos met die idee dat die voëls 'n stad tussen aarde en hemel moet stig. So kan hulle die mense oorheers en die offergeure van die

1 Sy naam word verskillend gespel - Peisthetairos of Pisthetairos, maar die meeste moderne uitgewers verkies die spelling Peisetairos.

2 Volgens die mite was Tereus met Prokne getroud maar het sy vrou se suster Philomela verkrag en daarna haar tong uitgesny. Prokne het egter uitgevind wat gebeur het, en uit weerwraak haar seun Itus gedood. Daarna is Tereus in 'n hoep-hoep, Prokne in 'n nagtegaal en Philomela in 'n swaeltjie verander. Van hierdie gewelddadige voorgeskiedenis word daar egter niks in die komedie gesê nie. 
gode afkeer sodat hulle uitgehonger word en gedwing word om die heerskappy van die voëls te aanvaar. Die hoep-hoep is geesdriftig en nadat hy 'n mooi lied aan sy vrou, die nagtegaal, gesing het, roep hy die voëls bymekaar. Soos hulle een vir een inkom, word hulle deur die hoep-hoep beskryf. Die Koor van die voëls verteenwoordig egter die Atheners, die voëls se groot vyande, die mense. Omdat hulle die voëls nie goedgesind is nie, wil hulle hul dadelik aanval en verskeur. Die Atheners maak reg om hulself met erdepotte te verdedig, maar die hoep-hoep slaag daarin om 'n wapenstilstand te bewerk. Dan vertel Peisetairos aan die voëls dat hulle oorspronklik die heersers was, maar deur die foute van hul voorvaders die heerskappy verloor het. As hulle egter sy plan aanvaar kan hulle hul mag herwin. Die voëls is nou vol geesdrif om die stad te bou en in die parabasis, 'n koorlied wat gewoonlik tot die gehoor gerig is, word daar vertel hoe die voëls, gebore uit Eros, eintlik die oudste bewoners van die aarde is, en watter voordele dit vir die mense sou hê om voëls te wees. Dit is tot hier dat Breytenbach van die oorspronklike komedie gebruik gemaak het. Die res van die drama bestaan uit 'n aantal los tonele waarin verskeie

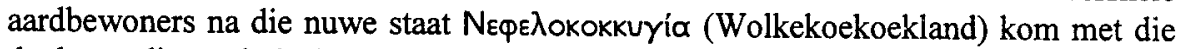
doel om dit tot hul eie voordeel te gebruik - twee digters, 'n waarsêer, 'n stadsbeplanner, ' $n$ inspekteur, ' $n$ handelaar in dekrete, 'n voornemende vadermoordenaar en 'n professionele aanklaer. Verder word met die gode onderhandel en 'n afvaardiging van die gode kom daar aan: dit bestaan uit Poseidon, Herakles en 'n barbaarse Triballiese god wat ' $n$ onverstaanbare taal praat. (Miskien het Breytenbach die idee vir die karakter Farenj met sy brabbeltaal hier gekry.) Herakles word gou verlei deur 'n lekker stuk gebraaide vleis en niemand kan die Triballiese god verstaan nie, sodat Poseidon teësinnig moet instem dat die heerskappy van die voëls erken word en dat die prinses Basileia aan Peisetairos as bruid gegee word.

Oor die "betekenis" van hierdie komedie is daar groot meningsverskil (sien Alink 1983:2-25). Dit is opgevoer in 414 v.C., net nadat 'n groot vlootmag van Athene na Sisilië vertrek het, 'n ekspedisie wat in 'n rampspoedige neerlaag geëindig het. Daarom wil baie kommentators in hierdie drama 'n veroordeling van die ekspedisie sien. Dit sou ooreenstem met Aristophanes se kritiek teen die oorlog met Sparta in vroeëre komedies. Die probleem is egter dat daar slegs drie moontlike sinspelings op die Sisiliaanse ekspedie is. Ander wil weer kritiek op die Atheense staat sien in die tekening van ' $n$ utopiese stad van die voëls. Nog 'n groep geleerdes sien die komedie as 'n poging tot ontvlugting uit die droewige werklikheid van daardie tyd. ' $n$ Interpretasie wat in die jongste tyd opgang maak, vind 'n ommekeer in die tweede helfte van die drama. Peisetairos wil 'n ideale stad stig, maar op die ou end word hy ook 'n tiran wat net so despoties optree soos sy voorgangers.

In haar nugtere inleiding sê Nan Dunbar $(1995: 3,5,12)$ dat daar geen bewyse is dat Aristophanes in hierdie komedie kritiese kommentaar lewer op die Sisiliaanse ekspedisie nie: "Aristophanes may have fully approved of the expedition." Hy teken ook nie 'n ernstige alternatief vir die Atheense staat nie: "...rather his

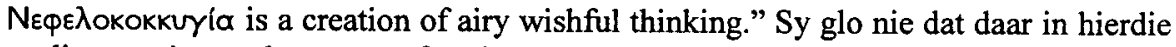
stadium so 'n sombere atmosfeer in Athene was dat die digter daarvan sou probeer ontvlug nie. Laastens reken sy dat die gehoor veronderstel word om Peisetairos as 'n 
simpatieke karakter te sien, selfs wanneer hy die leiding oorneem. Die veiligste is seker om, soos MJ Alink (1983:257), die sentrale tema in baie algemene terme te stel: "De Aves is een fantasiestuk, evenwel geen fantasiestuk zonder enig engagement; de Aves is zozeer betrokken op de politieke situatie in Athene dat het niet minder is dan een analyserend portret van de Atheense polis en een komische visie op de menselijke existentie zelf."

Alink (1983:254-256) maak verder 'n interessante opmerking oor die rol van taal in Die voëls: "Wel kan men stellen dat de toeschouwers in het reilen en zeilen van Pisetaerus en met name het gebruik van 'het wapen van het woord' zichzelf en de (politieke) situatie in Athene herkend zullen hebben", en kontrasteer daarmee die taal van die voëls: "Het terrein waarop ze de mensen met vlag en wimpel in die Aves verslaan is de taal, de zangtaal die zowel in het stuk zelf hemel en aarde ontroert als ook sinds de opvoering van de Aves de toeschouwers en leziers met grote bewondering heeft vervuld." Hy haal ook 'n gedig van Gerrit Kouwenaar aan, waarvan die volgende reëls besonder gepas is en interessante perspektiewe vir die interpretasie van Boklied bied: "de taal behoort aan de vogels / ik ben te mens om te vliegen...de taal behoort aan de vogels / de mens schuilt weg in het woord" (Alink 1983:255-256).

Hoe maak Breytenbach gebruik van Die voëls in sy drama? In die tweede bedryf van Boklied gebruik die dramaturg nou die digter-akteurs van die eerste bedryf om Aristophanes se komedie op te voer. Isis neem die rol van Peisetairos oor. Sy is oorspronklik 'n Egiptiese godin wat in die "Aanbeveling by opvoering" beskryf word as "'n swart Frida Kahlo, onbevange en wreed, maar ook wanhopig". Die rol van Euelpides word oorgeneem deur Ritsos wat sy naam kry van die Griekse revolusionêre digter. Die hoep-hoep word natuurlik gespeel deur Tereus, hoewel hy hier 'n patrys genoem word. As Koor gebruik die dramaturg slegs twee karakters Maker, "die skrywer", en Adam, sy assistent. Die ander twee karakters, Madonna en Farenj, is gedurende die hele bedryf net mekaar besig en steur hulle min aan wat op die verhoog gebeur.

In breë trekke met sekere weglatings en byvoegings, volg Breytenbach die handelingsverloop in Die voëls. Ritsos en Isis is op soek na die voëls. Uiteindelik kom Tereus te voorskyn uit die kis wat voor op die verhoog staan. In hierdie stadium begin die "paringsritueel" van Madonna en Farenj wat feitlik die hele bedryf as 'n soort "side-show" voortduur. Dit kom natuurlik nie uit Aristophanes nie! Ritsos vra Tereus uit na 'n plek waar hulle hul kan vestig en dieselfde toeligting word gegee as by Aristophanes: dit moet ' $n$ plek wees waar jy sommer so vir ete genooi word en kwalik geneem sal word as jy nie 'n jong seun molesteer nie. Tereus noem 'n paar plekke wat die besoekers nie aanneemlik vind nie en dan begin Isis haar plan uiteensit om 'n stad vir die voëls te bou. Nou word daar weer 'n toneel ingevoeg wat nie in die oorspronklike voorkom nie. Tereus sit gehurk met kaal boude na die gehoor gekeer, terwyl Ritsos en Isis allerlei opmerkings maak en selfs op sy boude teken. Aan die begin en einde van hierdie episode kry ons wel liedere aan die nagtegaal waarvan die eerste uit Aristophanes kom. Daarna word die voëls opgeroep. Die aanskoulike toneel by Aristophanes waarin die koms van die voëls beskryf word, moet die dramaturg 
uitlaat, want hy het slegs Maker en Adam om te gebruik. Hulle begin dadelik die besoekers met geweld dreig, maar Tereus kalmeer hulle. Isis kan dan, net soos Peisetairos, die voëls oortuig dat hulle vroeër heersers was en dat hulle ' $n$ voëlstad moet bou om die magte herwin. Aan die einde van hierdie toneel lewer Maker, as plaasvervanger vir die Koorleier, 'n hele betoog oor die oorsprong van die voëls en die voordele van voël-wees, net soos by Aristophanes. Voorbereidings vir die bou van die stad word getref, maar dan kom daar skielik 'n verandering. Tereus wil nog instruksies aan Ritsos gee, maar hy weier om dit uit te voer. Madonna raak skielik spraaksaam, maar wat sy sê het skynbaar geen verband met die res van die handeling nie. Adam sien 'n vreeslike gesig van geweld en die bedryf eindig op 'n somber noot met die sing van "Uit dieptes gans verlore".

Die vraag kom by 'n mens op waarom die dramaturg nou juis hierdie komedie gekies het om te verwerk. Die antwoord hierop is nie eenvoudig nie, maar daar kan wel gesê word dat ons in 'n sekere sin daarop voorberei word deurdat daar alreeds in die eerste bedryf 'n aantal verwysings na voëls is. Tereus word deur Maker verwelkom as 'n "common mossie"; dit is nogal vreemd want in die tweede bedryf is hy 'n patrys. Daar word verder gepraat van "bospatryseiers" en op 'n stadium sê Tereus sonder enige duidelike rede: "Patryse woon in die vou van die berge, as ek dit nie mis het nie" (bl.47). ${ }^{3}$ Die duidelikste sinspeling op die voëls van die tweede bedryf is miskien Maker se opmerking: "Julle het dopgehou, julle het ons die aard van die wanhoop gewys en julle leer ons die edele kuns van saambestaan, soos voëls in die paradys, al moet julle self ook die weg van alle vlees gaan" (bl.33). Aan die einde van die eerste bedryf is daar 'n duidelike oorgang as Tereus aangewys word as die een "wie se beurt dit vanaand is om ons die pad Paradys toe te wys", en Maker uitroep: "Die voël! Die voël! Viva die voël" (bl.56).

Wat vreemd is, is die veranderings in die name van sommige voëls. In die oorspronklike mite is Tereus verander in 'n hoep-hoep, maar hier is hy 'n patrys. By Aristophanes is die leeurik die eerste voël wat gebore word, maar volgens Isis is dit die aasvoël (bl.88). Peisetairos vertel dat die koekoek oor Egipte en Fenisië regeer het, maar volgens Isis is dit die piet-my-vrou (bl.89). 'n Eienaardige byvoeging is ook Madonna se woorde teen die einde van die tweede bedryf: "En as jy hierdie dinge volgens my opdragte uitvoer, dan sal jy soos 'n arend wees wat deur die wolke opstyg; maar as jy dit nie doen nie, en sou jy die geskenke nie gee nie, waarlik, dan sal jy nie ' $n$ arend wees nie, nee, nie eers 'n tortelduif nie, o nee, tot selfs nie ' $n$ geringe gespikkelde speg nie" (bl.100). ${ }^{4}$

Die gedeeltes wat hy net so uit die oorspronklike oorgeneem het, het Breytenbach weergegee in wat as 'n vrye parafrase beskryf kan word. Dit wissel van sinne wat klink soos 'n getroue vertaling van die Grieks, tot passasies wat 'n oorvertelling in 'n eietydse Afrikaanse idioom is. Dit is nie duidelik of die dramaturg 'n bepaalde vertaling geraadpleeg het nie, maar daar is soms treffende ooreenkomste met Dudley Fitts se weergawe, op ander plekke verskil dit weer heeltemal en is soms

Alle bladsyverwysings is na die uitgawe van Boklied deur Human en Rousseau, Kaapstad, 1998.

Hierdie hele passasie is eintlik oorgeneem uit 'n later episode waarin die Waarsêer vir Peisetairos instruksies probeer gee (vv.971-979). 
selfs nader aan die oorspronklike. 'n Interessante geval is die volgende: Wanneer die hoep-hoep verskyn, vra Peisetairos aan hom: "Is jy dan Tereus? Is jy 'n voël of 'n pou" (v.102). Dit is nie duidelik waarom die pou apart genoem word nie en kommentators meen dat 'n pou so onbekend vir die Grieke was dat hulle dit nie as 'n

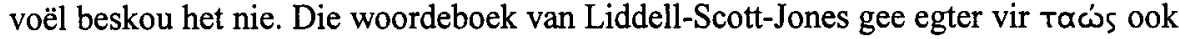
aan: "metaphorically of coxcombs". Dit het Fitts vermoedelik beweeg om te vertaal: "You are really Tereus? A bird or a parody?" Breytenbach se weergawe gaan nog verder: "Sê my, is jy 'n metafoor of 'n dolfyn?" (bl.65). Die motief van die dolfyn is origens belangrik in die drama, ${ }^{5}$ maar dit is baie vreemd dat dit hier genoem word. Dit is tipies van die vrye manier waarop die dramaturg met die oorspronklike teks omgaan.

'n Baie algemene verandering is die invoeging van kontemporêre verwysings, veral na die nuwe Suid-Afrika. Ek noem 'n paar van die interessantste verwysings. Peisetairos en Euelpides vlug van die ewige hofsake in Athene. Isis en Ritsos is "op soek na 'n heenkome sonder Versoeningskommissies of gekookte hofsake, 'n land sonder ' $n$ staat of amptelike staatsgeskiedenis of staatsdigters of cultural workers of televisiestront" (bl.62). Die hoep-hoep vra aan Peisetairos: "Jy soek duidelik 'n regering deur aristokrate?" By Breytenbach word dit die teenoorgestelde: "Ek neem aan julle is ten gunste van 'n demokratiese regering?" (bl.68). Die hoep-hoep stel verskillende Griekse stede as woonplek voor. Tereus vra vir Isis: "Hoekom gaan bly julle nie in Suid-Afrika, in Johannesburg tussen die wittes nie?" As sy dit van die hand wys, vra hy: "Wel, wat dan van die ander ouens, die swartes in Soweto?" (ble.69-70). 'n Vermaaklike verandering is die volgende: Die hoep-hoep sê dat 'n mens by die voëls sonder beursie moet lewe en Euelpides antwoord: "Dan het jy inderdaad baie bedrog uit die lewe weggeneem" (v.158). By Breytenbach merk Ritsos op: "Dan is die staat se subsidie ook in sy moer" (bl.70). 'n Soortgelyke byvoeging vind ons wanneer Tereus die voëls bymekaar roep en sê: "Dis goeie nuus. Ons aandele op die beurs gaan die hoogte inskiet" (bl.79).

Wanneer die voëls op Ritsos en Isis wil afstorm, vra hy haar hoekom sy hom saamgesleep het en sy antwoord: "Sodat jy my vertroude comrade mag wees, jou blerrie nat hoender! Jy, kamtig die behoeder van die armes en die wese en die weduwees en die swartes uit solidariteit met die Derde Wêreld" (bl.82). Tereus kalmeer die voëls egter deur vir hulle te sê dat die vreemdelinge "'n nuwe SuidAfrika" wil bou. In Isis se toespraak tot die voëls waarin sy hulle probeer oortuig dat haar plan vir 'n voëlstad 'n goeie idee is, kry ons ook sulke eietydse toevoegings. Die haan het oor die Perse regeer "lank voor daar sprake was van Darius of Megabazus of selfs: die Ajatolla Khomeini" (bl.89), en verder: "Die hele lug tussen Aarde en Hemel moet toegemaak word met 'n baksteenmuur soos Babilon of soos Berlyn" (bl.89). Peisetairos sê dat die gode nie meer toegelaat sal word om deur die voëls se gebied te gaan om sterflike vroue te verlei nie. By Breytenbach word dit: "En julle kan vir die vreemde gode, daardie trekarbeiders sê: Ramona, vat jy aan myne dan vat ek aan joune. Hulle sal nie meer toegelaat word om deur die elektriese drade te klim en so

5 Daar is heelwat verwysings na dolfyne in die drama, bv. op ble.49, 54 en 55; in die derde bedryf skenk Madonna die lewe aan in "dolfynknapie" (bl.142). 
maar ons meide te ryp nie" (bl.92). En as Maker namens die voëls die voorstel van Isis aanvaar, sê hy: "Ons sweer 'n eed dat jy saam met ons sal optrek teen die gode en die politici en die belastinggaarders en die bankiers en die voëlvangers" (bl.92).

Hierdie kontemporêre verwysings is natuurlik ingevoeg om die stuk nader aan die gehoor te bring en hulle te laat lag. Daar sou gesê kon word dat hulle in baie gevalle nou nie juis diepsinnig is nie. Hullle is egter heeltemal in die gees van die $\mathrm{Ou}$ Komedie wat wemel van verwysings na eietydse omstandighede en persone waarvan ons die betekenis baie dikwels nie kan agterhaal nie.

'n Ander opvallende kenmerk is dat hierdie bedryf baie doelbewus as teater aangebied word. Dit geld natuurlik vir die hele Boklied, maar is nog meer eksplisiet in die tweede bedryf, wat 'n spel-binne-'n-spel is. Isis en Ritsos word herhaaldelik as toneelspelers beskryf. Heel aan die begin, as hulle verdwaal is, vra Ritsos: "Dink jy jy sal die pad terug teater toe kry?" (bl.61). Isis kondig haarself en Ritsos aan as "karakters in 'n toneelstuk" (bl.66). Tereus vra dan aan hulle: "So julle soek 'n toevlugsoord wat groter is as hierdie teater van die dooies?", en later: "In watter soort opvoering wil julle dan vertoef?" (bl.68). Eindelik stel hy hulle aan die vyandige voëls voor as "twee rondreisende komediante", maar later sê hy dat hy nie seker is of hulle nie miskien "twee teaterresensente in drag" kan wees nie (bl.80). Nadat die voëls gekalmeer is, sê hy aan Maker: "Hulle wil 'n oudisie vir jou geselskap doen sodat hulle altyd by jou kan bly" (bl.84). Isis sien die voëls ook as akteurs as sy Tereus vermaan: "Nouja, in die eerste instansie moet jy ophou met jou onnosele gefladder van rol tot rol. Ek bedoel, mens sou sweer jy's 'n papegaai of ' $n$ trassie as mens jou so aangetrek sien. Kry vir jou een vaste identiteit en stig 'n stad" (bl.71). Tereus bied Isis se rede tot die voëls as teater aan: "Welkom by hierdie unieke aanbieding van die mees skouspelagtige show op aarde" (bl.79). Isis sluit hierby aan. As sy aan Maker vertel dat voëls voor die aarde bestaan het en hy sy verbasing te kenne gee, snou sy hom toe: "Het jy dan nie die program wat in die foyer verkoop word, gelees nie ?" (bl.88).

Behalwe hierdie meer spesifieke toepassings, is daar talle ander verwysings in ligte luim na toneelspelers en die teater. As Ritsos verbaas is oor Tereus se gebrek aan mooi vere, antwoord hy: "Nee, ons voëls verloor altyd ons vere in die loop van 'n opvoering, en dan kry ons nuwes" (bl.66). As Isis probeer om die voëls van hul belangrikheid te oortuig, sê sy: "En is dit nie waar dat toneelspelers selfs vandag nog, wanneer hulle hulle teks vergeet het, uitroep 'so by my Koekoek' in plaas van 'in die naam van Marx' nie" (bl.90). Nadat hy oortuig is, spoor Maker die ander tot aksie aan met die woorde: "Nog 'n bietjie sluimer, nog 'n bietjie slaap, dan kom die regisseur soos 'n bokwagter op ons af' (bl.92).

'n Belangrke byvoeging is die verwysings na die digters en digterskap. In die "Aanbeveling" staan daar: "Die karakters is almal digters." Peisetairos wil sy stad verlaat omdat die Atheners op hofsake versot is, maar Ritsos wil van (ander) digters wegvlug: “...digters praat jou 'n ganse verdomde lewe die ore van jou kop af, in howe en op politieke seepkiste en in stowwerige skouburge en op TV" (bl.62). Later noem hy aan Tereus 'n ander rede vir sy vlug: "Wel, jy was ook mens soos ons. En net soos ons het jy ook skuld gemaak - jy het ander mense se woorde geleen en hulle voorland 
gesteel" (bl.67). Die belangrikste passasie is egter dié waarin Isis haar plan vir die stigting van 'n voëlstad aan Tereus verduidelik. Peisetairos het gesê dat die voëls hierdie stad tussen hemel en aarde moet stig om die reuk van die offerandes wat van die mense na die gode opstyg, af te keer en so die gode uit te honger. Isis verander dit na die volgende: "Die lug is tussen hemel en aarde, dit wil sê tussen verhoog en ouditorium, reg? Nou ja, in die vervolg, wanneer digters offerandes vir die volk bring, sal die volk aksynsbelasting moet betaal, so nie laat julle nie toe dat daardie geurige vleisreuke julle gebied oorsteek nie" (bl.72). Sy verduidelik verder: "Die publiek daar, die afloerders (sy maak ' $n$ wye gebaar) - bring ons as verenigde digters van die wêreld dan nie ons offers juis vir hulle via die verhoog, hierdie heilige oorgangsgebied nie?" (bl.73). Dit is 'n enigsins moeilike opvatting, soos die dramaturg waarskynlik ook besef, want hy laat Ritsos opmerk: "Ek is glad nie so seker dat die ou teks baat by hierdie kontemporêre aanpassing nie", en hy verduidelik verder: "Wel, om die gode deur die volk te wil vervang, of die publiek dan, skep net verwarring. En ek is ook nie so seker oor jou dichotomie tussen digters en volk nie. Ons is ook mos maar mens. Sou dit nie beter wees as jy sê digters word vir die Party opgeoffer nie?" (bl.72). Ons kry hierdie gedagte weer as Isis beveel: "En julle moet 'n voël na die digters stuur om vir hulle te verduidelik dat hulle van nou af slegs vir die voëls offerandes mag bring..." (bl.92). Maar origens word hierdie gedagte nie konsekwent deurgevoer nie, want net na Isis se verduideliking sê Tereus: "Wat jy voorstel, mevrou, is dat ons voëls belasting hef op die reuk van offerandes, dis mos die gode se voedsel, wat deur ons gebied dryf' (bl.73). Dit stem ooreen met Aristophanes se oorspronklike idee. Later sing Maker en Adam, as Koor, 'n lied met dieselfde strekking: "Nooit weer / In ons gebied / Sal 'n god kom konkel...Nooit weer / Deur ons gebied / Sal die rook van altare kronkel..." (bl.99).

Daar is ander verwysings na digterskap wat somberder is en miskien vooruitwys na die offer van 'n digter wat in die derde bedryf gebring word. Ritsos sê in die begin aan Tereus: "Oftewel, waar ons vandaan kom, sê mens sekere soenoffers, as hulle poësie dit werd is, beland in die hemel as...as voëls" (bl.67). Later, wanneer Tereus met sy kaal boude gehurk sit, sê Ritsos: "Buitendien, ons is hier vir gewigtiger sake", en Isis verduidelik: "Vir die magiese formule van die laaste testament om ons finale gedigte te skrywe" (bl.77). Isis sweer "op die afgekapte kop van die Onbekende digter sonder hand" (bl.87). ${ }^{6}$ Eindelik sê Tereus vir Ritsos: "Of maak of jy 'n skrywer is en organiseer 'n rituele maaltyd en vermaak jou gaste met Aristophanus (sic) se Voëls" (bl.98).

Hierdie bevel bring ook die oorgang na die slot van die tweede bedryf. As Ritsos weier om te gehoorsaam, skryf hy op die skerm: "Maar 'n slagoffer is broodnodig." Adam sien 'n gesig van 'n ou man wat blykbaar tereggestel word. Die hele atmosfeer het verander. Maker begin bitterlik huil. Ons is voorberei op die offertoneel wat volg.

Ten slotte kom ons by die kernvraag waarom hierdie bedryf hoegenaamd in die drama ingevoeg is. Wat is nou eintlik die funksie daarvan? Hermien Dommisse (1998:13) sê dat dit in parodie op die onderhandelings tussen die destydse regering en 
CONRADIE

die ANC is. Daar mag elemente hiervan te bespeur wees, maar as die dramaturg dit werklik in gedagte gehad het, sou die tweede helfte van Die voëls, waarin die gode met die voëls onderhandel, vir hierdie doel baie meer geskik gewees het. Hein Viljoen (Horn 1998:11) beweer: "Hy (Breyten) gebruik Aristophanes se gedagte om die idee van 'n politieke utopie te parodieer. Dit verklaar baie van die bytende dialoog en lewer skerp politieke kritiek op die ou en nuwe orde." Daarteenoor vind Gabriel Botma (1995:4) die kommentaar op eietydse politiek maar "flouerig". 'n Finale antwoord op bogenoemde vraag is moeilik te gee, maar ek sou hier 'n ander moontlikheid wou suggereer. Die sentrale tema van die drama is dié van digterskap. Botma formuleer dit so: "Die kunstenaar word/skep God en vernietig Hom/self voordurend. Dit is die onontkombare lot van die lewe, en sy spieëlbeeld, die dood." Die atmosfeer in die eerste en derde bedryf is baie somber; daar word veral op die ontberings van die digter gekonsentreer Maar in die tweede bedryf is die digters op soek na die paradys en die hele vertoning word in ligte luim aangebied; die sub-titel van die bedryf is lucida intervalla wat vertaal kan word as "helder (vrolike) tussenspele". Die fantasie van voëls wat die wêreld oorheers, pas baie goed hierby in. Hein Viljoen (Horn 1998:11) verklaar dat veral in Breyten se tronkpoësie die voël as onbereikbare bevryding sterk na vore kom, en dit sou ook hier kon geld. Dit mag in 'n sekere sin 'n ontvlugting wees, maar dit belig ook 'n ander aspek van digterskap - die vrolike en fantasieryke element. En in hierdie opsig sluit die tweede bedryf baie goed aan by die heerlike fantasie van Aristophanes se komedie.

\section{BIBLIOGRAFIE}

Alink, M J 1983. De Vogels van Aristophanes. Een structuuranalyse en interpretatie. Amsterdam: Gieben.

Dunbar, N (ed) 1995. Aristophanes. Birds. Oxford: Clarendon Press.

Fitts, D (tr) 1958. Aristophanes. The birds. London: Faber.

Botma, G 1998. Maer Man se lied is kosbaarder as bok. Die Burger 4 April 1998:4.

Breytenbach, B 1998. Boklied. Kaapstad: Human en Rousseau.

Dommisse, H 1998. Boklied kan die dood van die Afrikaanse toneel inlui. Die Burger 23 April 1998:13.

Horn, A 1998. Bok in Boklied het ook familie in Griekse teater. Die Burger 30 April 1998:11.

Norval, R 1998. Sonder elite kunswerke "is dood in pot". Die Burger 23 Mei 1998:13. 